\title{
Particularidades de la relación entre el Consejo de asuntos económicos y el ecónomo en el Código de Derecho Canónico de Juan Pablo II
}

\author{
Special features of the relationship between \\ the Finance Council and the finance officer \\ in the Code of Canon Law by John Paul II
}

\begin{abstract}
The Finance Council and the finance officer support and work with the Bishop in the administration of the goods of the diocese. The relationship between the Council and the treasurer is not without some features, and the analysis of these peculiarities about this article. Both functions are presented and specific situations are discussed. Some concerning the various situations described, with special reference to the reality in Argentina statistical data are available. Suggestions aimed at optimal performance of their respective tasks are performed.
\end{abstract}

Keywords

Finance Council, finance officer, administration of the goods of the diocese.

La normativa codicial prevé dos instancias de colaboración para el Obispo respecto a la gestión de los bienes temporales de la diócesis: una de naturaleza 
colegial, el Consejo de asuntos económicos, y una de naturaleza personal, el ecónomo ${ }^{1}$.

El Consejo de asuntos económicos es obligatorio para todas las diócesis (canon $492 \$ 1$ ); de igual forma, el Obispo debe nombrar obligatoriamente un ecónomo (canon $494 \$ 1)^{2}$.

El iter redaccional de los cánones 492 a 494 nos muestra que en un comienzo fueron estudiados por el Coetus "De Bonis Ecclesiae Temporalibus", ya que la revisión estaba enfocada a la reelaboración del Código de 1917, pero posteriormente se determinó: "Normae de constitutione ac de competentia Consilii dioecesani a rebus oeconomicis necnon Oeconomi dioecesani habentur in alia parte novi Codicis (Lib. II, De Populo Dei) quia potius ad structuram Curiae dioecesanae pertinent"3.

También las figuras del Consejo de asuntos económicos y del ecónomo aparecían fundidas en una sola, debido a que el ecónomo fue ideado como presidente de ese Consejo; pero rápidamente se distinguieron ambas figuras: "distinguendum ese (...) directionem inter et exsecutionem. Prima fiat oportet per consilium, cui praeest Episcopus, altera vero per oeconomum, ne Episcopus per se negotia gerat"4.

En pocas palabras: "Consilio committenda est directio rei oeconomicae, oeconomo vero exsecutio" .

El Consejo de asuntos económicos, presidido por el Obispo, determina el modo de administrar los bienes de la diócesis por parte del ecónomo; y éste, bajo la autoridad del Obispo, administra los bienes del ente diócesis.

${ }^{1}$ Cfr. G. Incitti, La Chiesa particolare, en: Corso istituzionale di Diritto Canonico, Milano 2005, p. 223.

${ }^{2}$ Cfr. M. Landra, La constitución jerárquica de la Iglesia, en: A. A. López Romano (ed.) Nociones elementales sobre la ley de la Iglesia, Buenos Aires 2015, p. 111-112.

${ }^{3}$ Communicationes 9 (1977) 271; Communicationes 37 (2005) 287. Véase también V. De Paolis, Schema Canonum Libri V. De Iure Patrimoniali Ecclesiae, "Periodica" 68 (1979) 683-684.

${ }^{4}$ Communicationes 24 (1992) 53. Siendo el Obispo el centro de comunión del Pueblo de Dios, que está en la Iglesia particular “in quibus et ex quibus una et unica Ecclesia catholica exsistit” (actual canon 368), la norma codicial no podía sino confiarle a él la presidencia del Consejo de asuntos económicos; por otra parte, la presidencia del Obispo compete, además de por motivos teológicos y jurídicos, por motivos técnicos y funcionales que expresan el "exercitium iuris" del mismo Obispo. Cfr. F. R. Martinez Aguilar, Las normas sobre la administración económica en las Iglesias particulares. En especial su aplicación en el derecho particular del cono sur latinoamericano, Montevideo 1998, pág. 82.

${ }^{5}$ Communicationes 5 (1973) 228. Véase también Communicationes 9 (1977) 255. 
Vemos como entre el Consejo de asuntos económicos y el ecónomo se establecen relaciones jurídicas estrechas, ya que el ecónomo, para la administración de los bienes de la diócesis, además de seguir la línea indicada por el citado Consejo es controlado por éste por la rendición de cuentas de fin de año que debe efectuarle.

A su vez, el Obispo debe oír al Consejo de asuntos económicos para nombrar y para remover al ecónomo (canon $494 \$ \$ 1-2)^{6}$.

Tanto el Consejo de asuntos económicos como el ecónomo ayudan y colaboran con el Obispo en la administración de los bienes de la diócesis. Entre ellos debe existir una fluida interrelación, cada uno dentro del ámbito específico de su función ${ }^{7}$. Está relación, o interrelación, no está exenta de algunas particularidades, y al análisis de ellas se aboca el presente.

\section{Las funciones del Consejo de asuntos económicos}

Además de las funciones que se le encomiendan en el Libro V del Código de Derecho Canónico ${ }^{8}$, compete al Consejo de asuntos económicos, de acuerdo con las indicaciones recibidas del Obispo, hacer cada año el presupuesto de ingresos y gastos para todo el régimen de la diócesis en el año entrante, así como aprobar las cuentas de ingresos y gastos a fin de año (canon 493).

El canon $494 \$ 4$ habla de la rendición de cuentas de ingresos y gastos del ecónomo al Consejo de asuntos económicos. Este Consejo es quien establece los criterios generales sobre la administración de los bienes de la persona jurídica

${ }^{6}$ El Obispo debe hacer el nombramiento oídos previamente el Colegio de Consultores y el Consejo de asuntos económicos. La omisión de este proceder hace aparecer en escena al canon $127 \$ 1$, el cual nos dice que cuando el derecho establece que, para realizar ciertos actos, el Superior necesita el consentimiento o consejo de algún colegio o grupo de personas, para la validez de los actos se requiere obtener el consentimiento de la mayoría absoluta de los presentes, o bien pedir el consejo de todos. De allí que la consulta mencionada es necesaria para la validez del nombramiento del ecónomo. Lo mismo se aplica para el caso de remoción.

${ }^{7}$ Cfr. J. A. Di Nicco, ¿Puede ser miembro del Consejo de Asuntos Económicos quien desempeña el oficio de ecónomo? Propuesta sobre el parágrafo tercero del canon 492, "Ius Canonicum" 54 (2014) 792.

${ }^{8}$ Cfr. cánones 1263, 1277, $1281 \S 2,1287 \$ 1,1292 \$ 1,1305,1310 \$ 2$. 
diócesis. No expresa su juicio sobre cada una de las decisiones concretas, sino que establece las indicaciones que han de tenerse presente antes de ellas ${ }^{9}$.

$\mathrm{Al}$ inicio del año, el Consejo de asuntos económicos establece los capítulos de gastos sobre la previsión de entradas; es decir, prepara el presupuesto. El ecónomo lo ejecuta de acuerdo con el modo determinado por el Consejo (canon $494 \S 3$ ), y al final del año debe rendir cuentas de ingresos y gastos al mismo. Este Consejo, a fin de año, es quien aprueba o no la rendición de cuentas efectuada por el ecónomo.

Sobre este último particular, y con referencia específica al canon 493, Daneels señala que dicho canon habla de "probare" no de "approbare", sin especificar este autor la diferencia entre uno y otro término ${ }^{10}$.

Urso se pregunta si con esto se quiere decir que el Consejo de asuntos económicos sólo debe examinar las cuentas de ingresos y gastos pero no proceder a su aprobación. ¿Y quién aprueba entonces?, se interroga, ¿el Obispo? Urso dice que el Código de Derecho Canónico emplea el término "probare" también en el significado de “approbare", citando, a tal efecto, los cánones $26 ; 38 ; 276 \$ 2,3^{\circ}$; y $352, \S 2-3^{11}$.

La aprobación del informe por parte del Consejo da la certeza moral de que los recursos han sido utilizados, no sólo según las indicaciones dadas por el Obispo, sino también según los fines de la Iglesia ${ }^{12}$.

El Consejo de asuntos económicos tiene un mandato particular de la ley para examinar los informes anuales enviados al Obispo (canon $1287 \$ 1$ ), y también para examinar el informe preparado por el ecónomo de los recibos y gastos de la diócesis al fin de cada año (cánones 493 y $494 \$ 4$ ). A su vez, los datos de los informes serán usados para preparar los futuros presupuestos diocesanos ${ }^{13}$.

${ }^{9}$ Cfr. F. Coccopalmerio, Comentario al canon 494, en: Á. Marzoa, J. Miras y R. Rodríguez-Ocaña (ed.) Comentario exegético al Código de derecho canónico, Pamplona 2002, vol. II/2, p. 1135.

${ }^{10}$ Cfr. F. Daneels, De dioecesanis corresponsabilitatis organis, "Periodica" 74 (1985) 312.

${ }^{11}$ Cfr. P. Urso, La Chiesa particolare e la parrocchia come soggetti dellamministrazione di beni temporali, en: I beni temporali della Chiesa. XXII Incontro di Studio. Passo della Mendola Trento 3 Iugio- 7 Iuglio 1995, Milano 1997, p. 147.

12 Cfr. F. R. Martínez Aguilar, Las normas sobre ..., p. 98, 124-126.

${ }^{13}$ Cfr. A. Farrelly, The Diocesan Finance Council: Functions and Duties According to the Code of Canon Law, "Studia Canonica" 23 vol. 1 (1989) 158. Renken señala que hace varios años los Obispos de los Estados Unidos enviaron una resolución la cual precisaba que anualmente, al fin del año fiscal, cada Obispo sufragáneo debía enviar una carta a su Arzobispo metropolitano 
El Consejo de asuntos económicos formulará las directivas a partir del presupuesto estimable, pero siguiendo, también, el examen de la rendición anual de ingresos y gastos; debiéndose considerar las instrucciones necesarias a medida de la evolución de la administración del ecónomo durante el año, o cuando se estimen necesarias a causa de las dificultades encontradas en la ejecución de dicho presupuesto estimable. La frecuencia de las reuniones periódicas del Consejo de asuntos económicos dependerá de la situación económica particular de la diócesis ${ }^{14}$.

Propio del Consejo de asuntos económicos será dar los criterios sobre la administración de los bienes de la diócesis, siempre dentro de su condición "consultiva"15.

\section{Respecto a la confección del presupuesto}

En cuanto a la preparación del presupuesto por parte del Consejo de asuntos económicos al inicio del año, es de señalar una situación que se constata en varias diócesis argentinas, al igual que en otras diócesis de América del Sur.

Se argumenta que, debido a la variabilidad económica, la realización del presupuesto deviene imposible, ya que queda desactualizado en muy poco tiempo.

Tal planteamiento es fácil de rebatir, ya que el presupuesto puede actualizarse cuantas veces sean necesarias a lo largo del año.

El ecónomo a fin de año rinde cuentas de la ejecución del presupuesto, y si carece de éste qué pautas se tomarán en consideración para la evaluación de su rendición.

conteniendo, entre otras cosas, una declaración firmada por los miembros del Consejo de asuntos económicos y el ecónomo en la que declararen que ellos se habían reunido, repasado y discutido las declaraciones financieras de la diócesis. Cfr. J. A. Renken, The principles guiding the care of church property, "The Jurist” 68 (2008) 169-170, nota 51.

${ }^{14}$ Cfr. A. Nothum, Le Conseil diocésain pour les affaires économiques, en: S. Recchi (ed.), Autonomie financière et gestion des biens dans les jeunes Églises d'Afrique, Mbalmayo 2003, p. 107.

15 Cfr. J. Manzanares, Comentario al canon 493, en: BAC (ed.), Código de derecho canónico, Madrid 2001, p. 276. 
Al comienzo de cada año el Consejo de asuntos económico debe elaborar el presupuesto, y no hay ningún argumento que avale la posición en contrario, ni siquiera en condición de excepción.

La fluida interrelación entre el Consejo de asuntos económicos y el ecónomo es vital para detectar las variaciones en las pautas fijadas al comienzo del año por medio del presupuesto, y que el Consejo pueda realizar las adaptaciones pertinentes.

\section{Las funciones ordinarias del ecónomo diocesano}

Al ecónomo le corresponde, de acuerdo con el modo determinado por el Consejo de asuntos económicos y bajo la autoridad del Obispo, administrar los bienes de la diócesis (canon $494 \$ 3$ ); debiendo, para ello, disponer de los medios personales y materiales ${ }^{16}$.

El ecónomo debe administrar los bienes según el plan determinado por el Consejo de asuntos económicos; y, a su vez, con los ingresos propios de la diócesis debe hacer los gastos que ordene legítimamente el Obispo, o quienes hayan sido encargados por él ${ }^{17}$.

El ecónomo, como órgano ejecutivo, debe conocer profundamente las directivas y orientaciones del Consejo de asuntos económicos para realizar, conforme a ellas, su gestión ${ }^{18}$.

A fin de año, como se ha visto, debe rendir cuentas de ingresos y gastos al Consejo de asuntos económicos. Es decir, al ecónomo le compete la redacción de dicho informe, ello en atención a que lo largo del año lleva a cabo la ejecución del presupuesto aprobado por el Consejo de asuntos económicos, y al cabo del ejercicio debe rendir cuentas de esa ejecución al mismo Consejo ${ }^{19}$.

${ }^{16}$ Cfr. J. Goti Ordeñana, Financiación de la Iglesia, "Revista Española de Derecho Canónico" 58 (2001) 715 .

${ }^{17}$ Sobre este último particular, véase J. A. Di Nicco, El Ecónomo Diocesano Precisiones acerca de este oficio eclesiástico. Propuesta sobre el parágrafo tercero del canon 494, Buenos Aires 2012, p. 237-245.

${ }^{18}$ Cfr. F. R. Martínez Aguilar, Las normas sobre ..., p. 124.

${ }^{19}$ Cfr. H. A. von Ustinov, Organismos diocesanos de administración económica, en: La curia diocesana. Aspectos jurídicos y pastorales, Buenos Aires 2011, p. 84. 
El Código de Derecho Canónico no especifica cómo debe ser realizado en detalle el informe o reporte anual por parte del ecónomo; quedando esto a discreción del $\mathrm{Obispo}^{20}$.

Algunos autores hablan que el ecónomo debe presentar un "balance", cuando el Código habla de "cuentas de ingresos y gastos", y estos conceptos no son equivalentes.

La denominación de balance es genérica, aún cuando el término técnico responde a una situación anual, pero no sólo financiera sino también económica; en realidad se debería hablar de "estados contables", así en plural, puesto que están compuestos por diversos "estados".

Rendir cuentas de ingresos y gastos, en cambio, es elaborar y presentar un informe financiero correspondiente a un período determinado, generalmente, pero no excluyente, anual.

En el caso de referencia sería lógico titular dicha rendición como "reporte financiero anual" o, simplemente, como "reporte anual", pero no como "balance" 21.

Por último, es de precisar que el Obispo puede sumarle al ecónomo otras funciones además de las señaladas en el canon $494 \$ \$ 3$ y 4 , ello en atención a que por el canon 1278 puede sumarle las funciones indicadas en los cánones $1276 \$ 1$ y $1279 \$ 2^{22}$.

\section{4. ¿Puede ser miembro del Consejo quien desempeña el oficio de ecónomo?}

Del Consejo de asuntos económicos quedan excluidos, solamente, los parientes del Obispo, hasta el cuarto grado de consanguinidad o de afinidad (canon $492 \S 3$ ). El ecónomo no queda excluido, pero no parece adecuado que sea miembro de ese organismo.

${ }^{20}$ El reporte anual debe ser realizado a discreción del Obispo con el visto del Consejo de asuntos económicos quien dará los lineamientos a tal efecto. Tanto las copias de los lineamientos como de los informes anuales deben ser guardados en el archivo de la curia diocesana.

${ }^{21}$ Cfr. J. A. Di Nicco, El Ecónomo Diocesano ..., p. 103 nota 397.

${ }^{22}$ Sobre este particular puede verse J. A. Di Nicco, El Ecónomo Diocesano: su función ordinaria y las funciones adicionales del canon 1278 del Código de Derecho Canónico. Aspectos controvertidos, en: Sociedad Argentina de Derecho Canónico -SADEC- (ed.) XIV Jornadas Anuales, Mar del Plata 27 al 29 de octubre de 2015, Buenos Aires 2015, p. 132-141. 
A algunos autores les parece conveniente que el ecónomo sea miembro de este Consejo, o si no es miembro, al menos que debe ser llamado para aportar la información oportuna ${ }^{23}$.

Otros autores opinan que, dadas las funciones del Consejo de asuntos económicos, el ecónomo no debe pertenecer al mismo. Pero, teniendo en cuenta la inevitable relación que hay entre ambos, consideran que es necesario establecer algún cauce de comunicación entre ellos; por ejemplo, participando el ecónomo como miembro de ese Consejo con derecho a voz pero sin voto ${ }^{24}$.

Sobre este último particular se dice que parece conveniente la limitación de que tenga voz, pero no voto dentro del Consejo; ya que de lo contrario se daría una confusión por estar el ecónomo sujeto al control del Consejo: una confusión entre controlante y controlado ${ }^{25}$.

Hay quienes expresan que el ecónomo no debe integrar el Consejo de asuntos económicos, pero que es apropiado que asista a sus reuniones, opinión con la cual coincido ${ }^{26}$.

El canon 152 dice que a nadie deben conferirse dos o más oficios incompatibles, es decir, que no puedan ejercerse a la vez por una misma persona.

La incompatibilidad de oficios puede deberse a causas intrínsecas, extrínsecas o por ley positiva. Nadie podrá ser titular de dos oficios que no puedan ser encarnados plenamente por el mismo titular, sea la fuente de la incompatibilidad objetiva, subjetiva o legal.

Este principio de incompatibilidad no se establece ad validitatem, de donde no se seguiría la invalidez del nombramiento realizado sin respetarlo, a tenor de lo que señala el canon 10. Pero si la colación se verifica con un acto

${ }^{23}$ Cfr. L. Gutiérrez Martín, El régimen de la diócesis, Salamanca 2004, p. 84.

${ }^{24}$ Cfr. F. R. Aznar Gil, El ecónomo diocesano, en: F. Aznar Gil y J. San José Prisco (ed.), La curia diocesana. La función administrativa, Salamanca 2001, p. 310; Ibidem, El consejo diocesano de asuntos económicos, en: J. San José Prisco (ed.), La curia diocesana. La función consultiva, Salamanca 2002, p. 198-199.

${ }^{25}$ Cfr. A. Viana, Los Consejos diocesanos de pastoral y de asuntos económicos. Anotaciones desde el derecho particular, en: R. Serres López de Guereñu (ed.), Iglesia y Derecho. Actas de las Jornadas de Estudio en el XX aniversario de la promulgación del Código de Derecho Canónico, Madrid 2005, p. 145.

${ }^{26}$ Cfr. T. J. Green, Shepherding the patrimony of the poor: diocesan and parish structures of financial administration, "The Jurist" 56 (1997) 723-724; A. Nothum, Le Conseil diocésain ..., 109-110; D. Le Tourneau, Les Conseils pour les affaires economiques: origine, nature, "Il Diritto Ecclesiastico" 3-4 (1988) 614-615. 
administrativo, se ha de tener en cuenta que éste, ad validitatem, está bajo el principio de legalidad.

Lo importante es que la esencia del oficio pueda ser realizado por el titular en toda su integridad ${ }^{27}$.

El Consejo de asuntos económicos, con la presidencia del Obispo, toma las decisiones y el ecónomo las ejecuta; en pocas palabras, el ecónomo se encuentra sujeto al control del Consejo. Por ello, si el ecónomo es miembro del Consejo, se daría una confusión ente controlante y controlado.

A la luz de lo expuesto, considero que ambos oficios no resultan compatibles ${ }^{28}$.

\section{El caso del ecónomo eparquial}

El Código de Cánones para las Iglesias Orientales establece que el ecónomo eparquial es miembro de derecho del Consejo de asuntos económicos eparquial (canon $263 \$ 2)^{29}$, y que el Obispo eparquial debe determinar, más en concreto, los derechos y las relaciones del ecónomo eparquial con ese Consejo (canon $262 \$ 3)$.

La pertenencia explícitamente reconocida del ecónomo eparquial al Consejo de asuntos económicos, difiere de la solución adoptada en el canon 494 del Código de Derecho Canónico, en el que son oficios independientes ${ }^{30}$.

En el Código para la Iglesia latina la intervención del Consejo de asuntos económicos se requiere para la elección provisional de un ecónomo sede vacante, cuando el titular ha sido nombrado Administrador diocesano (canon $423 \$ 2$ );

${ }^{27}$ Cfr. B. Gangoiti, Comentario al canon 152, en: A. Benlloch Poveda (ed.), Código de Derecho Canónico edición bilingüe, fuentes y comentarios de todos los cánones, Valencia 2011, p. 98.

${ }^{28}$ Sobre el particular véase J. A. Di Nicco, ¿Puede ser miembro ..., 791-802.

29 Ver comentarios en L. Sabbarese, Comentario al canon 263, en: P. V. Pinto (ed.), Commento al Codice dei Canoni delle Chiese Orientali, Città del Vaticano 2001, p. 235; J. Manzanares, Comentario al canon 263, en: BAC (ed.), Código de Cánones de las Iglesias Orientales, Madrid 1994, p. 125.

30 "Consilio committenda est directio rei oeconomicae, oeconomo vero exsecutio". Communicationes 5 (1973) 228. Cfr. J. Manzanares, Comentario al canon ..., p. 125. "Si bien el ecónomo está en lógica relación con los integrantes del Consejo de asuntos económicos, no forma parte de él". H. A. von Ustinov, Organismos diocesanos de administración económica, en: La curia diocesana. Aspectos jurídicos y pastorales, Buenos Aires 2011, p. 84. 
para el nombramiento del ecónomo sede plena (canon $494 \$ 1$ ); y para la remoción del mismo sede plena (canon $494 \$ 2$ ).

Es competencia también del citado Consejo definir los criterios generales según los cuales el ecónomo debe administrar los bienes de la persona jurídica diócesis (canon $494 \$ 3)^{31}$.

A su vez, a fin de año, el ecónomo diocesano debe rendir cuentas de los ingresos y gastos a dicho Consejo (canon $494 \$ 4$ ).

Sobre la distinción existente en ambos Códigos Viana precisa: "En el CCEO, c. $263 \$ 2$, se establece que el ecónomo de la eparquía es ipso iure miembro del Consejo de asuntos económicos, pero hay que tener en cuenta que según el c. $262 \$ 4$ del CCEO el ecónomo rinde cuentas ante el obispo, sin perjuicio de la mediación del Consejo de asuntos económicos. En cambio, según el c. $494 \$ 4$ del CIC, el ecónomo diocesano debe rendir cuentas ante el Consejo, que determina además el modo de administración de los bienes de la diócesis bajo la autoridad del obispo (c. $494 \$ 3$ )"32.

Como se observa, la situación del ecónomo eparquial dista de la situación del ecónomo diocesano.

\section{6. ¿Puede el ecónomo ser el delegado del Obispo para presidir el Consejo de asuntos económicos?}

El canon $492 \$ 1$ del Código de Derecho Canónico dice que en cada diócesis ha de constituirse un Consejo de asuntos económicos presidido por el Obispo diocesano o su delegado.

En cuanto presidente, corresponde al Obispo convocar las reuniones facultad que puede otorgarle a su delegado-, aprobar el orden de las decisiones, procurar que se levanten las actas de las reuniones, etc. ${ }^{33}$

Del texto del canon $492 \$ 1$ se deja entrever que ni el Obispo, ni su delegado que lo presiden, son miembros del Consejo ni votan.

31 Ver F. Coccopalmerio, Comentario al canon 493, en: Á. Marzoa, J. Miras y R. Rodríguez Ocaña (ed.), Comentario exegético al Código de derecho canónico, Pamplona 2002, vol. II/2, p. 1124.

32 A. Viana, Los Consejos diocesanos de ...., p. 145 nota 59.

${ }^{33}$ Cfr. M. Medina Balam, Consejos de Asuntos Económicos: Diocesano y Parroquial, "Revista Mexicana de Derecho Canónico" 17/2 (2011) 333-334. 
El Obispo preside el Consejo pero no es miembro del mismo, como contrariamente sí lo era en el Código de 1917 (canon $1520 \$ 1$ ).

El delegado debe ser elegido de fuera del Consejo ${ }^{34}$. Si el delegado es miembro del Consejo su voto es inválido. En contrario a esto, algunos autores afirman que la persona designada puede ser tomada de entre los miembros componentes del Consejo ${ }^{35}$.

También hay autores que opinan que entre las facultades que podrían darse a un ecónomo se encontrarían las de convocar y presidir las reuniones del Consejo de asuntos económicos diocesano (canon $492 \$ 1)^{36}$.

Como se ha señalado, el ecónomo debería normalmente asistir a las reuniones del Consejo de asuntos económicos, pero sin tomar parte en las decisiones, porque no es un miembro, ni sustituir al delegado del Obispo, ya que esta función no se compadece con la de ecónomo ${ }^{37}$.

\section{Sede episcopal impedida o vacante}

Cuando la sede episcopal queda impedida, ni el Consejo de asuntos económicos ni el ecónomo cesan en sus funciones. Tampoco cesan al quedar vacante la sede episcopal, ya que el oficio de miembro del Consejo de asuntos económicos y el oficio de ecónomo no se pierden al cesar, de cualquier modo, el derecho de la autoridad que lo confirió (canon $184 \$ 2$ ).

El Código también establece que el Administrador diocesano no debe ser a la vez ecónomo; por ello, si éste al quedar vacante la sede episcopal es designado Administrador diocesano, el Consejo de asuntos económicos -convocado

${ }^{34}$ Cfr. A. Nothum, Le conseil diocésain ..., p. 103.

${ }^{35}$ Cfr. Á. Vizzarri, Il consiglio diocesano per gli affari economici. Diritto amministrativo della Chiesa sui beni temporali, "Monitor Ecclesiasticus" 119 (1994) 398; F. R. Martínez Aguilar, Las normas sobre ..., p. 83.

${ }^{36}$ Cfr. A. Asselin, Les laïcs au service de leur Église. Le point actuel du droit, Ottawa 2008, p. 220. Asselin tomó como base y remisión para este particular a J. Huels, Empowerment for Ministry: A Complete Manual on Diocesan Faculties for Priests, Deacons, and Lay Ministers, New York/Mahwah 2003, p. 195-199.

${ }^{37}$ Cfr. L. Gutiérrez Martín, El régimen de ..., p. 84; D. Le Tourneau, Les conseils pour ..., 614615, 619; J. A. Di Nicco, El Ecónomo Diocesano ..., p. 177-178; Ibidem, El delegado del Obispo diocesano para presidir el Consejo de asuntos económicos de la diócesis, "Anuario Argentino de Derecho Canónico" 19 (2013) 45. 
y presidido por el Administrador diocesano ${ }^{38}$ - elegirá provisionalmente otro ecónomo (canon $423 \$ 2$ ). Ésta es ciertamente una “magna facultas" del Consejo, dice Daneels, "praesertim si laicis constat"

El elegido "pro tempore oeconomum" cubrirá el oficio hasta que el nuevo Obispo tome posesión de la diócesis; momento en el cual el Administrador diocesano cesa en su oficio (canon $430 \$ 1$ ) y recupera su encargo precedente de ecónomo ${ }^{40}$.

\section{Algunas Estadistas}

A modo de complemento informativo sobre lo desarrollado, presentaré algunos datos estadísticos.

\section{a) Sobre el ecónomo como miembro del Consejo de asuntos económicos:}

Aznar Gil, en referencia a la situación en España al cierre del segundo milenio, decía que de 48 diócesis la encuesta indicaba que en 43 de ellas el ecónomo pertenecía al Consejo de asuntos económicos. En 34 con voz y voto, y en 9 con voz pero sin voto. Solamente en 5 se afirmaba que no pertenecía al Consejo, si bien en 3 de ellas asistía a sus sesiones con voz y sin voto, y en una de ellas como oyente ${ }^{41}$.

También Aznar Gil, pero al año 1985, expresaba que en 15 diócesis españolas el ecónomo era designado para integrar el Consejo en función del cargo que desempeñaba ${ }^{42}$.

${ }^{38}$ Cfr. R. Walczak, Sede vacante come conseguenza della perdita di un ufficio ecclesiastico nel Codice di Diritto Canonico del 1983, Roma 2008, p. 188.

${ }^{39}$ Cfr. F. Daneels, De dioecesanis corresponsabilitatis ..., 313.

${ }^{40}$ Cfr. L. Chiappetta, Prontuario di diritto canonico e concordatario, Roma 1994, p. 497; R. Walczak, Sede vacante come ..., p. 188; Á. Vizzarri, Il consiglio diocesano ..., 431.

41 Cfr. F. R. Aznar Gil, El ecónomo diocesano ..., p. 320.

${ }^{42}$ Cfr. F. R. Aznar Gil, La nueva organización económica de las diócesis españolas, en: El derecho patrimonial canónico en España. XIX semana española de derecho canónico, celebrada en Salamanca del 17 al 21 de septiembre de 1984, Salamanca 1985, p. 205. 
Morrás Etayo, también para España pero al cumplirse los diez primeros años del Código, decía que, entre las características comunes a todos los Consejos según la legislación particular, se apreciaba la pertenencia al mismo del ecónomo por derecho propio. Señalaba que en el $80 \%$ de la diócesis el ecónomo pertenecía a dicho Consejo, si bien en alguna de ellas tenía voz pero no voto; y que en alguna diócesis se había dejado la vicepresidencia del mismo en sus manos ${ }^{43}$.

En Italia, Redaelli trae a colación el artículo 10 del Reglamento del Consejo de asuntos económicos de la diócesis de Milán, fruto directo del Sínodo diocesano concluido en Milán el 7 de diciembre de 1994 y promulgado el 1 de febrero de 1995, donde se prevé la presencia, no como miembro sino como participante, sin derecho a voto pero si con posibilidad de intervención, del ecónomo. Es decir, se prevé que el responsable del oficio administrativo y el ecónomo, el primero para aquello relativo a personas jurídicas sujetas al Obispo y el segundo para aquello del ente diócesis y de los entes centrales, contribuyan con su específica competencia y su experiencia a la organización o formación de las deliberaciones del Consejo (Redaelli transcribe íntegramente el Reglamento) ${ }^{44}$.

Sobre este aspecto la Conferencia Episcopal Italiana dispuso que considerando que el "consiglio per gli affari economici e il collegio dei consultori sono organi de controllo e di vigilanza, è bene che l'economo [...] non ne faccia parte, ma partecipi alle sedute come relatore e/o como segretario" 45 .

En Argentina, al año 2009, de las Iglesias particulares integrantes de la provincia eclesiástica Buenos Aires ${ }^{46}$, se observa que en cuatro de ellas el ecónomo es miembro del Consejo y en las siete restantes no lo integra. De estas últimas, en dos de ellas en forma periódica asiste a las reuniones y puede emitir opinión; y en otra participa sólo en caso que sea necesaria su presencia ${ }^{47}$.

$\mathrm{Al}$ año 2015, y en un porcentaje de consulta próximo al cuarenta por ciento de las diócesis argentinas, en varias diócesis el ecónomo integra el Consejo, y en algunas de ellas por derecho propio.

${ }^{43}$ Cfr. J. L. Morrás Etayo, El consejo diocesano de asuntos económicos en las diócesis españolas, "Revista Española de Derecho Canónico" 53 (1996) 238-240.

${ }^{44}$ Cfr. C. Redaelli, I regolamenti del collegio dei consultori e del consiglio per gli affari economici della diocesi, "Quaderni di Diritto Ecclesiastico" 9 (1996) 111, 115, 124-130.

${ }^{45}$ Conferenza Episcopale Italiana, Istruzione in materia amministrativa, 1 settembre 2005, n. 26.

${ }^{46}$ Reúne un total de once Iglesias particulares.

47 Cfr. J. A. Di Nicco, El Ecónomo Diocesano..., p. 233-235. 
En Brasil, también al año 2015, sobre once diócesis consultadas, en tres de ellas el ecónomo integraba el Consejo.

\section{b) Sobre el ecónomo como delegado del Obispo para presidir el Consejo:}

En Argentina, al año 2013, de las Iglesias particulares integrantes de la provincia eclesiástica Buenos Aires, se observa el caso de una diócesis donde el ecónomo -laico- además de integrar el Consejo de asuntos económicos era delegado del Obispo para presidirlo ${ }^{48}$.

$\mathrm{Al}$ año 2015, de una consulta cercana al treinta por ciento de las diócesis argentinas, no se encuentra al ecónomo como delegado del Obispo para presidir el Consejo.

En España, como se ha visto en el punto precedente, Morrás Etayo decía, al año 1993, que en alguna diócesis se había dejado la vicepresidencia del Consejo de asuntos económicos en manos del ecónomo.

\section{c) Sobre el presupuesto:}

$\mathrm{Al}$ año 2015, de una consulta cercana al cuarenta por ciento de las diócesis argentinas, la realización del presupuesto por parte del Consejo de asuntos económicos se observa en un número ínfimo.

\section{d) Sobre la rendición anual de cuentas de ingresos y egresos:}

La consulta respecto a la rendición anual de cuentas de ingresos y egresos por parte del ecónomo se ha podido materializar, entre los años 2014 y 2015, en un porcentaje cercano al cuarenta por ciento de las diócesis argentinas.

El resultado muestra que en su mayoría se da cumplimiento con la normativa canónica. La rendición se efectúa a fin de cada año, o a comienzos del año siguiente. La forma de realizar la rendición no es uniforme, aunque se coincide en el contenido de las mismas en sus lineamientos generales.

Hay tres datos de interés para señalar:

1) En un caso el ecónomo no presenta la rendición, ni tampoco se le es exigida.

${ }^{48}$ Cfr. J. A. Di Nicco, ¿Puede ser miembro ..., 797. 
2) En otro, el ecónomo la presenta anualmente pero el Consejo no se expide sobre ella.

3) También se aprecia el caso que el ecónomo solamente presenta el informe cuando cesa en su oficio.

A lo expuesto hay que sumarle que, a excepción de un número ínfimo como fuera dicho, la rendición se efectúa sin que se haya redactado el presupuesto al inicio del año.

En Brasil, al año 2015 y sobre un total de once diócesis consultadas, en todas se daba debido cumplimiento con la presente normativa canónica.

\section{e) Sobre la periodicidad de las reuniones del Consejo de asuntos económicos:}

$\mathrm{Al}$ año 2015, de una consulta próxima al cuarenta por ciento de las diócesis argentinas, se aprecia una gran diversidad sobre el particular:

1) Reuniones mensuales.

2) Dos reuniones al año, una al comienzo del año y otra al finalizar el año.

3) Reuniones solamente en caso de necesidad.

4) Se detectan dos situaciones donde se superó el año sin realizarse ninguna reunió por parte del Consejo de asuntos económicos.

\section{Conclusión}

Del desarrollo del presente se desprende la fluida interrelación que debe darse entre el Consejo de asuntos económicos y el ecónomo para que sean la debida ayuda y colaboración que el Obispo necesita en la administración de los bienes de la diócesis.

Dadas las funciones del Consejo de asuntos económicos, el ecónomo no debe pertenecer al mismo; pero es conveniente que asista a sus reuniones con derecho a voz.

Tampoco debe ser el delegado del Obispo para presidir las reuniones del Consejo.

Entre el Consejo y el ecónomo debe establecerse un permanente cauce de comunicación.

Fundamental es la realización del presupuesto por parte del Consejo, y la rendición de la ejecución del mismo por parte del ecónomo a fin del año. 
Lorenzo Santos dice que "ambas figuras se ven necesitadas de un mayor desarrollo normativo, que naturalmente - y en buena lógica - corresponde efectuar al Derecho particular" ${ }^{\prime 9}$.

Las legislaciones particulares deberían determinar con mayor detalle algunos aspectos de la constitución, miembros y funciones del Consejo de asuntos económicos; normas que tienen que estar contendías en los estatutos ${ }^{50}$.

Es prioritario, que tanto el Consejo de asuntos económicos como el ecónomo, conserven su rol y se interrelacionen de manera conveniente para el óptimo cumplimiento de sus respectivas tareas, y de esa forma sean la herramienta de colaboración adecuada que el Obispo necesita para la administración de los bienes de la diócesis.

\section{Bibliography}

Aznar Gil F. R., El consejo diocesano de asuntos económicos, en: J. San José Prisco (ed.), La curia diocesana. La función consultiva, Salamanca 2002, p. 183-209.

Coccopalmerio F., Comentario a los cánones 492-494, en: Á. Marzoa, J. Mirás y R. Rodríguez - Ocaña (ed.), Comentario exegético al Código de Derecho Canónico, Pamplona 2002, vol. II/2, p. 1119-1135.

De Paolis V., Schema Canonum Libri V. De Iure Patrimoniali Ecclesiae, "Periodica" 68 (1979) 673-713.

Di Nicco J. A., El Ecónomo Diocesano. Precisiones acerca de este oficio eclesiástico. Propuesta sobre el parágrafo tercero del canon 494, Buenos Aires 2012.

Di Nicco J. A., El Ecónomo Diocesano: su función ordinaria y las funciones adicionales del canon 1278 del Código de Derecho Canónico. Aspectos controvertidos, en: Sociedad Argentina de Derecho Canónico - SADEC - (ed.), XIV Jornadas Anuales, Mar del Plata 27 al 29 de octubre de 2015, Buenos Aires 2015, p. 119-142.

Di Nicco J. A., ¿Puede ser miembro del Consejo de asuntos económicos quien desempeña el oficio de ecónomo? Propuesta sobre el parágrafo tercero del canon 492, "Ius Canonicum" 54 (2014) 791-802.

Goti Ordeñana J., Financiación de la Iglesia, "Revista Española de Derecho Canónico” 58 (2001) 699-748.

${ }^{49}$ D. C. Lorenzo Santos, La reforma de las curias diocesanas en España a partir del CIC 83, en: La curia diocesana. La función administrativa, Salamanca 2001, p. 68.

${ }^{50}$ Cfr. J. B. Solís Espino, Relación entre el consejo de asuntos económicos y el ecónomo diocesano, "Universitas Canonica" vol. 29 nº 45 (2012) 21. 
Green T. J., Shepherding the patrimony of the poor: diocesan and parish structures of financial administration, "The Jurist" 56 (1997) 418-441.

Gutiérrez Martín L., El régimen de la diócesis, Salamanca 2004.

Incitti G., La Chiesa particolare, en: Corso istituzionale di Diritto Canonico, Milano 2005, p. 199-236.

Landra M., La constitución jerárquica de la Iglesia, en: A. A. López Romano (ed.), Nociones elementales sobre la ley de la Iglesia, Buenos Aires 2015, p. 85-118.

Manzanares J., Comentario al canon 263, en BAC (ed.), Código de Cánones de las Iglesias Orientales, Madrid 1994, p. 125.

Martínez Aguilar F. R., Las normas sobre la administración económica en las Iglesias particulares. En especial su aplicación en el derecho particular del cono sur latinoamericano, Montevideo 1998.

Medina Balam M., Consejos de Asuntos Económicos: Diocesano y Parroquial, "Revista Mexicana de Derecho Canónico" 17/2 (2011) 329-358.

Nothum A., Le Conseil diocésain pour les affaires économiques, en: Autonomie financière et gestion des biens dans les jeunes Églises d'Afrique, Mbalmayo 2003, p. 91-130.

Renken J. A., The principles guiding the care of church property, "The Jurist" 68 (2008) 136-177.

Solís Espino J. B., Relación entre el consejo de asuntos económicos y el ecónomo diocesano, "Universitas Canonica” vol. 29 nro. 45 (2012) 11-30.

Ustinov H. A. von, Organismos diocesanos de administración económica, en: La Curia diocesana. Aspectos jurídicos y pastorales, Buenos Aires 2011, p. 77-85.

Viana A., Los Consejos diocesanos de pastoral y de asuntos económicos. Anotaciones desde el derecho particular, en: R. Serres López de Guereñu (ed.), Iglesia y Derecho. Actas de las Jornadas de Estudio en el XX aniversario de la promulgación del Código de Derecho Canónico, Madrid 2005, p. 115-146. 